\title{
Homo faber juvenalis: A Multidisciplinary Survey of Children as Tool Makers/Users
}

\section{David F. Lancy}

\begin{abstract}
The overall goal of this paper is to derive a set of generalizations that might characterize children as tool makers/users in the earliest human societies. These generalizations will be sought from the collective wisdom of four distinct bodies of scholarship: lithic archaeology; juvenile chimps as novice tool users; recent laboratory work in human infant and child cognition, focused on objects becoming tools and; the ethnographic study of children learning their community's toolkit. The presumption is that this collective wisdom will yield greater insight into children's development as tool producers and users than has been available to scholars operating within narrower disciplinary limits.
\end{abstract}

Keywords: infants, children, juvenile chimpanzees, work, tools

\section{Becoming Tool Makers/Users}

This paper aims to enlarge our sparse picture of children's role in early Hominin tool culture derived, largely from lithic archaeology. This will be accomplished by drawing on complementary areas of scholarship, specifically, chimpanzee tool learning and practice; relevant studies in human infant and child cognition and; the cultural anthropology of children's playful and purposeful use of tools. The paper identifies themes in the complementary areas that reinforce or strengthen suggestive results from studies of early (juvenile) humans.

"Becoming" is used in the sense of ontogeny or the process whereby a naive child learns to use tools. "Becoming" also refers to the fact that, for tool use to spread and endure among Hominids, children or juveniles had to serve as the conservators retaining the tool, its manufacture and use in the culture (Grimm 2000). In this survey, “... a tool is perceived as an extension of the body that is used to achieve a goal that cannot be directly achieved with the use of only hands or teeth" (Boesch 2014, 24). A foundational premise of the survey-derived largely from cultural anthropology — is that children begin early to carry out real or simulated tasks which accomplish 
a practical end (e.g. fetching water). Further, that childhood is pervaded by chores the majority of which involve the use of tools (Lancy 2015a, 2016). Children's work is integral to the domestic economy and to the child's development as a mature, successful individual. There is considerable variability in how quickly children are expected to master the subsistence skills of adults and just how much they're expected to contribute to the family economy (Lancy 2015b). However, even in cases like the Ju/'hansi (!Kung) where children are in their teens before they are expected to become proficient contributors to the larder, the very young will already be busy making and using smaller, somewhat less effective food gathering tools such as bows and arrows and digging sticks (Liebenberg 1990; Wilhelm 1953).

\section{Children as Stone Tool-Makers}

The nature of flint knapping is such that researchers are able to reassemble or refit the original stone core from the resultant tool and associated waste flakes or debitage. Stone tool making sites tended to be used for extended periods or episodically, hence most sites yield a large cache of worked stone to analyze. With the growing interest in the archaeology of childhood (Kamp 2015), investigators are paying increased attention to stone products that are faulty in some way. The typical site, in fact, reveals the presence of expert knappers, beginners and those who are moving along from one state to the other (Stapert 2007). Fortuitously, the debitage from a novice's efforts is recoverable as none of the products are useable (Karlin and Julien 1994). Abandoned, incomplete cores show precisely where the novice went wrong. The idea that becoming an expert takes a great deal of practice is evidenced by the fact that errors are patterned and predictable such as evidence of "stacked step scars, hinge terminations and hammer-marks on the core faces" (Bamforth and Finlay 2008, 6).

These inferences from field study are supported by contemporary replicative knapping experiments in which novice knappers are given the material and opportunity to create a stone tool. Their work is compared with that of expert knappers from whom data has also been obtained and from the archive of pre-historic tools and debitage (Cunnar 2015). In a contemporary expert vs novice comparison - of hand-axe construction - the researchers identified three problems which the novices had to overcome (Beribas et al. 2010). Another, similar study found that all novices struggled with the problem of applying too much or too little 
force Shelley 1990) — a failing shared by chimpanzee novices — suggesting the importance of trial and error.

From another study, we learn that some egregious errors - using the wrong end of an antler tine to hammer a biface, for example - are easily avoided when the novice can observe an expert (Carroll 2016). Similarly, Ferguson (2003) compared two groups of novices. One group worked in consort with an expert and had ample opportunity for observation. They made more rapid progress and wasted less material than the comparison group who received direct instruction followed by practice. Another study with two groups of novice knappers provided either a competent model only or a model plus verbal instruction on how to make bi-facial tools. Verbal instruction hindered students who struggled to precisely imitate or over-imitate whereas the nonverbal group focused on the goal and through greater trial and error, achieved success more rapidly (Putt et al. 2014).

Study of stone knapping of adzes, axes and knives by living New Guinea highlanders found that “...copying, and trial and error, rather than explicit teaching, are certainly the methods by which Duna learn about flaked stone" (White et al. 1977, 381). In a comparable study in a stone working site in the Hunsgi-Baichbal Valley in India, the authors report “...interpersonal observation in quarries is common, and learning takes place by watching skilled workers...making groundstone tools" (Petraglia et al. 2005, 216).

Grimm (2000) asserts that flint knapping required a great deal of practice and would, necessarily, commence in childhood. There are three reports of contemporary knappers that are relevant. In one, the archaeologist knaps a stone arrow point — without any further explanation — at the request of his 5 year-old nephew. He was amazed to observe the child 6 weeks later at the same site, busily knapping found material to produce a reasonable facsimile of his uncle's work, including flaking the core bi-facially. The article concludes that "Very young individuals can begin learning to knap through social observation" (Shipton and Nielsen in press; also Petraglia et al. 2005; Hawcroft and Dennell 2000). 
The duration of the novice phase varies. In a study done in the Gona area of Ethiopia, knappers working in trachyte improved rapidly in attempting to match a model. However, when the same novices tried producing the tools using quartzite the task became much harder (Stout and Semaw 2006). The authors speculate that learning the characteristics of various types of stone under stress is an important corollary of learning to make tools. The study and use of properly finished tools must also facilitate learning to make them. Tools offer affordances (Gibson 1979) or clues to how they are best used or made (Caruana et al. 2014).

While it may be beneficial for children to begin to learn at an early age, children younger than, perhaps eight or nine, may not have acquired sufficient muscle mass and sensorimotor skill to successfully produce certain tools. Studying the debitage from expert knappers, it is clear that making a hand axe, for example, involves several distinct steps which must be executed in a particular order (chaîne opératoire cf. Leroi Gourhan 1964). Consequently, “...learning knapping routines required...specific actions involved in achieving sub-goals... organized into a hierarchical structure of tool production" (Caruana et al. 2014, 268).

The social setting or work-space is also important. Hampton (1999) photographed a stone knapping workshop in the PNG Highlands This was a semi-circular ensemble of boys, ranging in age, each knapping at whatever level of skill they had reached and a single adult knapper positioned at the apex. Variations on this image of a social group composed of beginner to expert tool makers, arranged in a particular pattern, are not uncommon. At Etiolles, (14,000 years BP) the work-space was roughly circular with the most productive workers in the center, nearest the hearth. Less proficient knappers were stationed at a corresponding distance from the center with child novices at the periphery where they could watch while "play" knapping but without getting in the way (Pigeot 1990). A very similar distribution of knappers was excavated at Pincevent, a contemporary site (Julien and Karlin 2015). From a dart-making site in the Great Basin of North America "the 'poor' preforms... are positioned in an arc around the excellent knapper"'(Cunnar 2015,143).

Children may have moved through the work-space and gathered larger, discarded tools to remove to more peripheral "play" areas. Here, they played with "real," if flawed, tools in sight of 
experts making them. This is very much in line with the proposal that children are "legitimate peripheral participants" (Lave and Wenger 1991) and, also, that "being a 'toy' is a potential characteristic of all objects in a child's environment" (Crawford 2009, 55). The workplace is decidedly social (Stout 2002) - as noted below for chimpanzees, and in most pre-industrial, small-scale societies - which creates a "relaxed field" for children to play near adults without fear.

Another cultural adaptation that supports the novice's training is the provision of poorer quality material to practice on. Stone tool-making inevitably produces a great quantity of waste material while suitable, high quality raw material may be difficult to obtain (Stout 2002). Novices may find or be given stone that can be worked but otherwise unlikely to yield a useable tool. At an Upper Paleolithic site in the Netherlands, "children practiced on used-up cores abandoned by expert knappers" (Stapert 2007, 21). As we will see, chimpanzees also show a differentiation between good quality stones used by mothers for nut-cracking and ready-to-hand stones used by juveniles for practice.

Overall, the optimal learning environment appears to one where the novice can learn socially with an expert role model as well as peer models and be afforded the scope for extended practice and improvement over several years. Instruction, as such, may not be helpful.

Before the second millennium B.C.E. the archaeological record is relatively silent on children as tool users (but see Thompson and Nelson 2011). Child burials in ancient Mycenae (and records written in Linear B) often include tools the child may have used for weaving, basketry and leather-working and for the preparation of clay tablets (Gallou 2010). More recent sites elsewhere have yielded crude "toy" tools made of wood rather than bone or stone (Kenyon and Arnold 1985). Studies of tool-rich Arctic foragers point to children being introduced to critical tools via miniatures that may not have been functional but were used in "make believe" hunting, for example (Park 2005).

\section{Juvenile Chimps and Tools}


Studies of chimp behaviour in the wild are now considered vital in understanding the origins and capacities of the Homo line and that is particularly true for the study of the juvenile period in human life history. "Vast domains of human child-rearing... are largely shared in common with apes" (Konner 2010, 564). Studies in the wild show widespread but variable use of an extremely diverse tool-kit by chimpanzees, hence increasing attention has been given to the study of juveniles as novice tool users. Infants remain largely attached to their mothers. Later, the young will still remain in close proximity for up to five years. Therefore, juveniles enjoy a front-row seat at the mother's continuous performance of food gathering/processing and social (social grooming) chores. The fact that they are learning while observing is borne out in long-term studies of nut cracking. Once mobile, the juvenile tends to manipulate and transport stones that resemble his nut-cracking mother's anvil and hammer. More generally, the objects they choose to play with look more and more tool-like as they mature (Koops et al, 2015)

The centrality of observation in their development as tool users is demonstrated in studies of "ant dipping." Bossou and Gombe mothers varied in the time they spent catching army ants. Those who spent more time dipping, but provided no further facilitation, had youngsters who picked up the skill sooner with better results (Humle et al. 2009; Lonsdorf 2006). In two further cases, inmigrant chimps who had learned nut-cracking elsewhere served as role models for naive resident chimps. Juveniles were more attentive and successful in picking up the skill than adults (Matsuzawa 1994; Marshall-Pescini and Whiten 2008). In a controlled study carried out in a Ugandan sanctuary, young chimps who observed a model cracking and eating palm nuts had no difficulty learning the skill while others, who had access to the material but no role model, handled the three objects (anvil, hammer and nut) and hit one against the other but never chanced upon the correct arrangement and behavior sequence (Marshall-Pescini and Whiten 2008).

Trial and error or practice is also critical. A long-term study of novice nut-crackers found that they had learned the five basic actions Take, Put, Hold, Hit, and Eat by 1.5 years. However, it took 3.5 years for novices to refine the process achieving a workable trio of objects and a sequence of actions with those objects which result in cracking open and exposing an intact nut (Inoue-Nakamura and Matsuzawa 1997). 
In many primate species, including those that do not use tools, foraging may be "gregarious." The foraging group is relatively tolerant of juveniles in their midst (Sanz and Morgan 2014). Juveniles can learn a great deal from observing where more mature animals search for food, what they find and what they do with it (e.g. consume it, discard it or add it to a collection that will be later processed). They also observe adults securing material and making tools for food extraction (e.g. ant twigs, nut-crackers). Two Bossou chimps learned entirely from others as their mothers did not practice nut-cracking (Inoue-Nakamura and Matsuzawa 1997). Mothers may facilitate learning by providing close visual access to their tool use and, more rarely, direct access to their tools (Boesch 1995). The learner enjoys a thorough visual, tactile, kinesthetic and even gustatory (the juvenile may "steal" and eat processed food) inspection. However, mothers seem more tolerant of older juveniles who are focused and making steady progress (Matsuzawa et al. 2001). This transition occurs earlier in females (Koops et al, 2015) who more closely observe their mothers. Young males are less attentive and more rambunctious (Lonsdorf 2005).

However, the degree of tolerance or facilitation seems to vary widely across troops and among mothers within those troops (Boesch 2013), a pattern also observed in the ethnographic record (Lancy 2015a). Regardless of the amount of facilitation by the mother, younger learners are making progress through play with objects. Among these are discarded tools and detritus from tool use to examine and learn from. They develop an understanding of the properties or affordances of various objects, particularly sticks and stones (Sanz and Morgan 2014). An early study of captive juveniles found that the chimps who were permitted to play with objects (sticks) before-hand, used them more effectively to solve problems than chimps without the prior play episode (Birch 1945). This preparatory phase also occurs in learning to use stone tools. Juveniles manipulate and wield hammerstones before they can effectively hammer with them, hence, when they "start attempting to nut-crack...they can already make all kinds of corrections to improve their performance, such as changing...the angle they are hitting the nut...the hammers they are using, and so on" (Boesch 2013,147).

Variability in the curve for learning varous tools noted from lithic studies also applies to chimpanzees. They exploit palm, coula and panda nuts. While all three are cracked using a hammer and anvil, the last is extremely hard and may take years to master (Boesch 2013)—while 
cracking the soft palm nut may be learned in days (Marshall-Pescini and Whiten 2008). Even a skill as apparently simple as ant fishing or dipping may take years to perfect (Yamamoto et al. 2008).

In spite of these challenges, field observors have sought in vain for evidence of active teaching by experts in nut-cracking or other skill areas. Mothers do not guide or shape juvenile hand movements and "active teaching in wild chimpanzees is either nonexistent or occurs only in very few and exceptional cases" (Matsuzawa et al. 2001, 571). Vocal communication appears unconnected to tool-use (McGrew 1993). Mothers provide no "social reinforcement" or any useful feedback (Inoue-Nakamura and Matsuzawa 1997). Investigators studying Orangutans in the wild have also failed to record instances of teaching. Immature orangutans learn by closely observing their mothers (Jaeggi et al. 2010).

\section{The Ontogeny of Tool Use}

The next body of work that can shed light on children and tools falls, roughly, under the rubric of “infant cognition." Researchers in lab settings study the infant's attention as they process the stream of information - aural, visual and tactile - in their environment. Babies show interest by glance, lingering gaze and an increase in sucking. Interest may be provoked by alterations in the information flow, in particular, violations of "normal" patterns. By noting what attracts and holds an infant's attention, scholars infer awareness, perception and understanding or at least the engagement of thought. The work with infants is complemented by lab studies with children aged 12-48 months.

\section{Imitation and Object Exploration in Year One}

Virtually from birth, infants demonstrate an extraordinary talent for imitation. Six-month-old infants imitate body movements, especially hand movements and facial expressions. At this age, they have no difficulty with delayed imitation, reproducing gestures they'd seen modeled a day earlier (Meltzoff 2002). Infants are also using all of their sense organs to "explore" objects in their environment (Rochat 1989). They pay particular attention to what people they observe do with objects. Tests show that they discover patterns in such use and are surprised when their expectations are violated. For example, six-month-olds look to the mouth when they see a person 
grasp a cup and to the ear when they see her pick up a phone. And they show surprise when the model brings a cup to the ear or hairbrush to the mouth (Hunnius and Bekkering 2010). This occurs well before they can carry out such actions themselves. From this milestone, infants move along to decoding the operational features of the object, noting that "containers" like cups, can hold things, for example. "Infants pay attention to an artifact's physical features that causally contribute to the achievement of a goal" (Hernik and Csibra 2009, 35). These uniquely human adaptations are said to "facilitate the acquisition of knowledge about material culture" (Hernik and Csibra 2009, 34, italics added), e.g. tools.

As their coordination develops, infants attempt to reach, touch and manipulate objects. From two-to-five months, they expand their multi-modal exploration of objects to using their hands and mouths. By three months they modify their exploratory actions to fit the physical properties and affordances of the object. Such manipulation enhances what they have learned already from observing others. Simple grasping evolves into more systematic manipulation: "infants finger textured objects more than non-textured ones, shake or bang sounding objects more than nonsounding ones and press pliable objects more than non-pliable ones" (Bourgeois et al. 2005: 233). In the process, they are constructing some general principles about the nature of objects and their relationship to the environment - naive physics (Stahl and Feigenson 2015). There is probably no need for an innate "tool use" adaptation because, a suite of biases that influence object handling make it "increasingly likely that [children] will learn to use objects as culturally prescribed" (Bjorkland 2016, 9).

Infants do a lot of banging. Recent studies have attempted to discover the patterns underlying what at first may seem like random behavior. Banging began to look like a "hammer curriculum" as studies showed that it followed a clear, consistent developmental progression. Steady improvement led to the result that "at the end of the first year, object banging had become well suited for percussive tool use" (Kahrs and Lockman 2014, 234). More generally, it appears that, before children handle actual tools, they've learned a great deal about the qualities of objects and how objects transform the capacities of their bodies: "individuals are at some level registering that the properties of their arms or hands have been changed by virtue of the object they are holding" (Bourgeois et al. 2005, 235). 


\section{From Object Exploration to Tool Use in Years Two-Three}

There is somewhat of a gap between the study of the child's object exploration and use and the study of early tool use. In contemporary, post-industrial society, children have little need to learn to use tools. But, in one, now classic, study, the investigators carefully documented children's mastery of the spoon from 12-23 months-perhaps the first tool to be used successfully by a child in our culture. The skill of using a spoon is built in a broadly similar way by different infants. Initially, rudimentary actions with the spoon are observed and these serve a number of purposes. They provide a means whereby the infant learns something of the mechanical properties of the spoon, and they also anchor the ends of the process. The launch pad is the dish with its food, and the destination is the infant's mouth. Significantly, the child persists at attempting to use the spoon, gradually perfecting the skill; but, until mastery, no food finds its way to his mouth (Connolly and Dalgleish 1989). "Success striving seems to be a universal motivation" (Weisfeld and Linkey 1985).

The nascent skills revealed in year one continue to expand and become more refined and effective. As with chimpanzees, they show that infants who are free to manipulate tools or toollike objects are more readily able to $\underline{\text { use }}$ those objects to solve a problem than children without this opportunity (Caruso 1993).

Much of the child's exploration can be characterized as "play" and scholars assign a role to object play "in helping children discover...how objects can be used as tools" (Bjorklund and Gardiner 2010, 153). Several studies affirm a link between object play and tool use: "for all participants, object-oriented play was significantly and positively related to tool use scores" (Schulz and Bonawitz 2007, 164). When children of this age observe a model using a tool to accomplish a specific end, they treat the tool as iconic. Children make this association quickly and, in experimental studies, two-year-olds protest when a puppet uses a tool for the "wrong" purpose. "... such rapid tool-function mapping provides strong evidence that normative, socially learned beliefs about function are at the core of artifact understanding, even for very young children" and this tendency strengthens from ages two-to-three" (Casler et al. 2009, 241). I see an analogy here to the child's language acquisition device; that is, the child readily fills-in a tool 
template from the several information sources available. "Hammer" quickly emerges and stabilizes: its shape; appearance; name; affordances; function and; sensorimotor system (the act of hammering) coalesce into a single, enduring concept (Casler and Kelemen 2005). At any time in the future the child will know a hammer when she sees one, she'll know how to hold it and how to make it do its work.

While neonates may imitate a model indiscriminately, by one to one and a half, children focus as much on the task or problem as they do on the specific behaviors of the model. Between fourteen and eighteen months, infants develop the ability to discriminate between a model's intentional actions and her "accidents" (Carpenter et al. 1998). Fifteen-month-old children can discriminate between an effective and an ineffective tool when used by a model (Elsner and Pauen 2007) and they will imitate a demonstrator's problem solving strategy "only if they consider it to be the most rational alternative. [Hence] imitation of goal-directed action by preverbal infants is a selective, interpretative process" (Gergely et al. 2002, 755; also Keupp et al. 2015). If the demonstrator succeeds in the task, but, in the process, produces some irrelevant or unnecessary actions, fifteen-month-old children will, eliminate them when given a chance to solve the problem. "Infants appear to "filter" [the model's] actions according to their own intentions, assessing each action for its importance to fulfilling these" (Brugger et al. 2007, 814).

Studies of prosocial or helping behavior are relevant. In several studies eighteen-month-old children were shown to eagerly and persistently volunteer to help an adult complete a task. They produced appropriate verbalizations and showed they understood the goals of the tasks, "even adding appropriate behaviors not modeled by the adults" (Rheingold 1982, 114). Evidently, "young children have an intrinsic motivation to act altruistically" (Warneken and Tomasello 2009). Cross-culturally, volunteer collaboration and assistance by very young children is nearly universal and has been, informally, labelled "pitching in" (Paradise and Rogoff 2009). Rogoff and her colleagues, who have long studied this process, call attention to the learning opportunities that direct involvement with others who are completing a task provide. As they explain, children observe and attend with greater effort and intensity when they have to prove their worthiness to become a participant (Rogoff et al. 2003). 


\section{Autonomous Learning in Years Three-Five}

Research with children in their third and fourth year continues to highlight the child's autonomous learning. Earlier, I cited a claim that learning to knap involved the mastery of several tasks and their integration in a hierarchical structure of tool production (Caruana et al 2014). In at least one experimental study of child cognition, three-year-olds were capable of successfully imitating a model (without any explicit guidance) in carrying out a complex, multistep task (opening an "artificial fruit"). Component tasks and the hierarchical structure that organized them were "clearly copied" (Whiten 2002, 111). It is evident from this and other studies that the child is "in charge," using the model's behavior as a kind of instructional video, rather than being a dutiful pupil following the model's direction. Children are clearly drawn to observing those older and/or more competent. They can sort several models from more to less competent and selectively attend to the best model. And they can accurately judge when a model is using a "bad" or a "good" tool. "Preschoolers are not indiscriminate imitators of others"

intentional tool use and show selectivity about who and what they copy" (Di Yanni and Kelemen 2008, 250).

Pre-schoolers were given an opportunity to explore a multi-faceted, multi-function toy. Various conditions were imposed, in particular, a pedagogical and an unconstrained introduction to the toy. In their subsequent exploration and play, children who were exposed to instruction, focused entirely on the function(s) demonstrated while the unconstrained discovered several additional functions through greater exploration of the toy. This "channeling" effect of teaching was evident when the child was the subject of instruction and also when the child only observed an instructional session directed at other children (Bonawitz et al. 2011). Also, "schooled" children, compared to "un-schooled" or lightly schooled children, are less able to learn through observation, relying on teacher instruction and texts (Correa-Chavez and Rogoff 2005). Children's attention to what the teacher wants "made them worse at actually learning" (Gopnik 2016, 107).

\section{Children and Tools in the Ethnographic Record}

There is a long tradition of using the ethnographic record to shed light on the distant past (Lupo and Schmitt 2002) and “ethnographic research is useful for the exploration of children's 
relationships with the physical and material world" (Thomas 2005, 27). In this section, I will briefly summarize some of the prominent findings in the study of children becoming tool users and makers.

\section{Playing with Knives}

The Mayan infant, while stationery and quiet, is "attentively observing her surroundings, laying the foundation for later observational learning" (Greenfield et al. 1989). Similarly, Matsigenka "Infants and young children are embedded in the middle of quotidian activities where they are positioned to quietly observe and learn what others are doing" (Ochs and Izquierdo 2009, 395). Once the child is walking, it will be granted more freedom to venture some distance away from its mother and manipulate found objects, including tools. In many societies, a large knife or machete is often one of the first such "targets of opportunity" (Lancy 2016). John Whiting (1941), studying the Kwoma in the Sepik Region of Papua New Guinea provided one of the earliest of many records of toddlers (or younger!) handling, or, in this case, mouthing knives - in full view of adults. When challenged by the ethnographer, a common parental response underscores the child's autonomy and of the futility of trying to impose one's will on a "senseless" child (Broch 1990). A second response is that it is only through, direct, hands-on interaction with tools that children learn to use them. And, if children have free-rein to learn tool use this obviates the need for someone to instruct them (Lancy 2010).

\section{Figure 1. Matses toddler with a knife}

When "real" tools are unavailable, various substitutes come into play. A Chewong child may be given an old, blunt knife (Howell 1988). But broken, cast-off objects are often simply lying around the village much like the incomplete or discarded stone tools available to the Acheulian child. A Kammu child may be given a functional "toy" knife made of bamboo or hardwood (Tayanin and Lindell 1991). Nukak foragers provide boys of the right age smaller blow-pipes (Politis 2007). Mayan girls are given simple but useable toy looms to learn on (Greenfield 2004). In parallel with chimp mothers only permitting older, more capable offspring access to their tools, so too, humans seem to provide well-made "practice" tools only after a certain level of diligence is achieved (Wilhelm 1953). Tools and tasks are matched to the child's ability. A 
Hadza girl's productivity as a forager grows with the size of her digging stick (see cover photo Crittenden 2016). In the absence of tools made expressly for children, they will to construct their own tool inventory. Girls make dolls, digging sticks, baskets and string bags consonant with their emerging roles. Nukak boys make a wide array of crude, small, but still quite functional tools (Politis 2007).

\section{Figure 2. Matses boys hunting}

The prevalence of "sib-care" typically involves the young child in play with older sibs as well as observing and helping as she or he does chores. Consequently, Mayan "toddlers learn primarily by observing and interacting with their sibling caretakers" (Maynard 2002, 978). The "minders" may still be using smaller scale tools and work with them more slowly than adults. Their skills are, then, much more accessible than an adult's.

The use of the qualifier "toy" in designating child-sized tools correctly signals that the object will be used in play and that the child is not expected to complete a chore using the tool or make a significant contribution to the family larder. As I indicated, children have access to found objects and, as soon as they are mobile, they will become as readily engrossed in exploring their properties, as the children in the lab experiments described earlier. The earliest sign that the child has begun to think of the object as a tool occurs when the child's movements with it mirror those of someone using such a tool. The "delayed" imitation described earlier for infants is seen most clearly in make-believe play. The ethnographic record is especially rich in descriptions of children's make-believe which, inevitably, replicates the work activities they observe in their community. I recorded a multi-player, extended make-believe session among Kpelle children that was based on the children's observations at the blacksmith's forge. The boy/blacksmith "in charge" of the play group had carefully fabricated facsimiles of the smith's bellows, anvil, tongs, hammer and so on. He directed his "cast" in their roles as apprentices and journeymen using the replica tools, while the girls busied themselves preparing "dinner" for the smiths (Lancy 1996). Not surprisingly, play transitions seamlessly to work. The children will soon employ the processes and tools replicated in make-believe in "real" chores. "Watching [Hadza] 3-4-year- 
olds [one] realizes that [they] are not just playing but are actually digging small tubers [with a digging stick] and eating them" (Marlowe 2010, 156

\section{The Necessity for Effective Models}

In addition to the freedom to explore, manipulate and attempt to use real tools, children must also be able to observe competent users in order to become fully proficient. Adults express gratification when a child makes a concerted effort to closely observe and replicate the process of tool making and/or use. This expectation flows from the belief that parents "do not presume to teach their children what they can as easily learn on their own" (Guemple 1979, 50). And this belief is usually proved by events. Children on Samoa were observed trailing after and watching expert fishers. Sometime later they "borrowed" the equipment (nets, spears) to practice the techniques they had observed. This led, eventually, to proficiency even though "they never used fishing gear in an expert's presence, nor did an expert offer instruction" (Odden and Rochat 2004, 44).

\section{Figure 3. Ifaty Village boys participate in turtle butchering}

\section{Summary and Conclusions}

Woven together, these four strands of research exhibit several points of convergence. Like chimp juveniles, Hominin babies would have focused their attention on people and things, especially when they were joined - a mother wielding a tool or eating a fruit. From birth, they had sensory and cognitive capacities that gave them a head-start in making sense of their world to guide their later attempts to master it. Babies were always in close proximity to their mothers-for ease of feeding — but human infants had multiple caretakers/role models to interact with and observe. Human infants and toddlers display a rich array of evolved traits and behaviors that are clearly adaptive for tool-using cultures. These adaptations do not depend on speech and may have appeared earlier than language.

A picture emerges of juveniles as eager to explore their environment, particularly objects - a necessary stage in the child's development as a tool user-as shown in experimental studies with 
infants and toddlers. Objects, and, especially tools, offer affordances which guide the child in discovering the tool's properties. In fact, every object has a story to tell.

Children show clear enjoyment as they handle various tools or pseudo tools in play. Infantsalmost from birth - observe and imitate con-specifics. They soon develop the capacity for delayed imitation where observation is somewhat later followed by replication. These emerging abilities set the stage for make-believe play which incorporates and expands upon object play. Play episodes place tools in a social context, reinforcing their use and importance in the regular work of the household. Given the ubiquity of tool-linked play in the ethnographic and crosscultural and archaeological records, we can infer that this avenue for learning how to make and use tools is of great antiquity.

Among humans and chimpanzees, once the learner displays interest and intiative, an adult may facilitate learning by making and donating a toy tool, passing on an old tool or, occasionally, "loaning" a useable tool. In stone knapping sites, children had access to both cast-off incomplete tools and low value raw material that could be used for practice. The latter may have been supplied by adults.

Observation and imitation are the primary means by which children learn so, it is not surprising to find these skills emerging early. These complementary behaviors in the ontogeny of tool use and fabrication is echoed in all of the research strands reviewed, including modern knapping experiments. The possibility of knapping (or learning) circles at stone tool making sites suggests that the best knappers worked in a location that supported close observation by an array of less competent tool-makers, including children. These same sites suggest that very young children, lacking the dexterity or strength to create useable tools, nevertheless had ample opportunities to practice flaking in a playful way but with one eye on the expert. Village children and juvenile chimps are also found in close proximity to tool-wielding adults where they are welcome if they do not interfere.

Research with infants learning to use tools, such as the spoon example, show steady improvement over time and this occurs in predictable patterns. Steady repetition or practice over 
time, leading, gradually, to mastery also appears in lithic studies. We do not know at what age children began to focus on tool-making. In the ethnographic context, children are observant helpers by three and tool makers (digging sticks, for example) and users by six with very evident "steps" in-between. A similar transition occurs with chimpanzees where their interaction with tools remains playful and unfocussed until they mature. For the more difficult applications like Panda nut cracking, it may take several years until mastery.

The length of a child's apprenticeship would depend on the nature of the tool and the material from which it was made. In the ethnographic record, children usually may learn at their own pace, likely to be the case with Neolithic hunter-gatherers as well. It may be that not all individuals mastered the entire tool-kit. Among contemporary hunter-gatherers, bows and arrows, for example, are often fabricated exclusively by specialists.

Children in the ethnographic record also learn by volunteering to help out. If they gain entry to a work party (butchering game, for example) they will not only observe processes at close hand, they can practice tool use in a real-world context, receiving tacit feedback as to their competence. Chimpanzee mothers may also exhibit some tolerance for would-be partners. In these social situations, children are doubly motivated - to master the task and, to be socially accepted and valued.

Replicative knapping experiments indicate that teaching may actually retard the novice's progress. Among chimpanzees, teaching is extremely rare. In the experimental literature with infants and toddlers, teaching — of skills associated with tool-using — has negative side-effects. In the ethnographic record, teaching is rarely observed and often condemned by informants as unnecessary and possibly harmful to the child's development as a worker. There is, rather, appreciation for self-initiated learning.

\section{Acknowledgements}

I am grateful to Jennifer Deliskave for assistance with editing and to Siân Halcrow, Alyssa Crittenden and two anonymous reviewers for very helpful feedback on earlier drafts of the paper. 


\section{References}

Bamforth, Douglas B. and Nyree Finlay. 2008. "Introduction: Archaeological Approaches to Lithic Production Skill and Craft Learning." Journal of Archaeological Method and Theory 15: $1-27$.

Beribas, Núria, Marina Mosquera, and Josep M. Gerges. 2010. "What Novice Knappers Have to Learn to Become Expert Stone Toolmakers.” Journal of Archaeological Science 37: 2857-2870.

Bjorkland, David F. 2016. "Incorporating Development into Evolutionary Psychology." Evolutionary Psychology. 14 (4): 1-14.

Bjorklund, David F., and Amy K. Gardiner. 2010. “Object Play and Tool Use: Developmental and Evolutionary Perspectives." In The Oxford Handbook of Play, edited by Anthony Pellegrini, 153-171. New York: Oxford University Press.

Boesch, Christophe. 1995. "Aspects of Transmission of Tool-Use in Wild Chimpanzees. In Tools, Language and Cognition in Human Evolution, edited by Kathleen R. Gibson and Tim Ingold, 171-183. Cambridge: Cambridge University Press.

Boesch, Christophe. 2013. Wild Cultures: A Comparison Between Chimpanzee and Human Cultures. Cambridge: Cambridge University Press.

Boesch, Christoph. 2014. "Ecology and Cognition of Tool Use in Chimpanzees." In Tool Use in Animals: Cognition and Ecology, edited by Crickette M. Sanz, Josep Call, and Christophe Boesch, 21-47. Cambridge: Cambridge University Press.

Bonawitz, Elizabeth, Patrick Shafto, Hyowon Gweon, Noah D.Goodman, Elizabeth Spelke, and Laura Schultz. 2011. “The Double-Edged Sword of Pedagogy: Instruction Limits Spontaneous Exploration and Discovery." Cognition 120:322-330. 
Bourgeois, Kristine, Alexa W.Kwahar, S. Ashley Neal, and Jeffrey J. Lockman. 2005. "Infant Manual Exploration of Objects, Surfaces and Their Interrelations.” Infancy 8: 233-252.

Broch, Harald B. 1990. Growing up Agreeably: Bonerate Childhood Observed. Honolulu: University of Hawai'i Press.

Brugger, Amy, Leslie A. Lariviere, Donna L. Mumme, and Emily W. Bushnell. 2007. “Doing the Right Thing: Infants' Selection of Actions to Imitate from Observed Event Sequences." Child Development 78:806-824.

Carpenter, Malinda, Nameera Akhtar, and Michael Tomasello. 1998. "Fourteen Through Eighteen-Month-Old Infants Differentially Imitate Intentional and Accidental Actions." Infant Behavior and Development 21: 315-330.

Carroll, Sean T. 2016. Tracking Flintknapper Skill Variation Through Debitage: An Experimental Approach. Unpublished MA Thesis, University of Wyoming Department of Anthropology.

Caruana, Matthew V., Francesco d'Errico, and Lucinda Backwell. 2014. "Early Hominin Social Learning Strategies Underlying the Use and Production of Bone and Stone Tools." In Tool Use in Animals: Cognition and Ecology, edited by Crickette M. Sanz, Josep Call, and Christophe Boesch, 242-285. New York: Cambridge University Press.

Caruso, David A. 1993. “Dimensions of Quality in Infants' Exploratory Behavior: Relationships to Problem-Solving Ability." Infant Behavior and Development 46: 331-454.

Casler, Krista, and Deborah Kelemen. 2005. "Young Children’s Rapid Learning about Artifacts." Developmental Science 8: 472-480.

Casler, Krista, Treysi Terziyan, and Kimberly Greene. 2009. “Toddlers View Artifact Function Normatively." Cognitive Development 24: 240-247. 
Connolly, Kevin, and Mary Dalgleish. 1989. "The Emergence of Tool-Using Skill in Infancy." Developmental Psychology 25: 894-912.

Correa-Chavez, Maricela and Barbara Rogoff. 2005. "Cultural Research has Transformed our Ideas of Cognitive Development." International Society for the Study of Behavioral Development Newsletter 47(1): 7-10.

Crawford, Sally. 2009. “The Archaeology of Play Things: Theorizing a Toy Stage in the Biography of Objects." Childhood in the Past 2: 56-71.

Crittenden, Alyssa N. 2016. “Children's Foraging and Play among the Hadza: The Evolutionary Significance of 'Work Play." In Childhood: Origins, Evolution, \& Implications, edited by Courtney L. Meehan, and Alyssa N. Crittenden, Santa Fe, NM: School for Advanced Research Press.

Cunnar, Geoffrey E. 2015. "Discovering Latent Children in the Archaeological Record of the Great Basin." Childhood in the Past 8: 133-148.

Di Yanni Cara, and Deborah Kelemen. 2008. Using a bad tool with good intention: young children's imitation of adults' questionable choices. Journal of Experimental Child Psychology 101:241-261.

Elsner, Birgit, and Sabina Pauen. 2007. "Social Learning of Artifact Function in 12- and 15Month-Olds.” European Journal of Developmental Psychology 4: 80-99.

Ferguson, Jeffrey R. 2003. "An Experimental Task of the Conservation of Raw Material in Flint Knapping Skill Acquisition.” Lithic Technology 28(2): 113-131. 
Gallou, Chrysanthi. 2010. "Children at Work in Mycenaean Greece (ca. 1680-1050 BCE): A Brief Survey." In Childhood and Violence in the Western Tradition, edited by Laurence Brockliss and Heather Montgomery, 162-171. Oxford: Oxbow Books.

Gergely, György, Harold Bekkering, and Ildikó Király. 2002. "Rational Imitation in Preverbal Infants." Nature 415: 755.

Gibson, James J. 1979. The Ecological Approach to Visual Perception. Boston: Houghton Mifflin.

Gopnik, Alison. 2016. The Gardener and the Carpenter: What the New Science of Child Development Tells Us About the Relationship Between Parents and Children. New York: Farrar, Straus and Giroux.

Greenfield, Patricia M. 2004. Weaving Generations Together: Evolving Creativity in the Maya of Chiapas. Santa Fe, NM: School of American Research Press.

Greenfield, Patricia M., T. Barry Brazelton, and Carla P. Childs. 1989. "From Birth to Maturity in Zinacantan: Ontogenesis in Cultural Context.” In Ethnographic Encounters in Southern Mesoamerica: Celebratory Essays in Honor of Evon Z. Vogt, edited by Victoria Bricker and Gary, 177-216. Albany, NY: State University of New York Press.

Grimm, Linda 2000. "Apprentice flintknapping: Relating material culture and social practice in the Upper Paleolithic.” In Children and Material Culture, edited by Joanna S. Derevenski, pp. 53-71. London: Routledge.

Guemple, D. Lee. 1979. "Inuit Socialization: A Study of Children as Social Actors in an Eskimo Community." In Childhood and Adolescence in Canada, edited by Karigoudar Ishwaran, 39-71. Toronto: McGraw-Hill Ryerson. 
Hampton, O. W. "Bud." 1999. Culture of Stone: Sacred and Profane Uses of Stone among the Dani. College Station: Texas A\&M University Press.

Hawcroft, Jennie and Dennell, Robin 2000. "Neandertal Cognitive Life History and its Implications for Material Culture. In Children and Material Culture, edited by Joanna S. Derevenski, 89-99. London: Routledge.

Hernik, Mikolaj, and Gergeley Csibra. 2009. "Functional Understanding Facilitates Learning about Tools in Human Children." Current Opinion in Neurobiology, 19: 34-38.

Howell, Signe. 1988. "From Child to Human: Chewong Concepts of Self.” In Acquiring Culture: Cross Cultural Studies in Child Development, edited by Gustav Jahoda and Ioan M. Lewis, 147168. London: Croom Helm.

Humle, Tatyana, Charles T. Snowdon, and A. Tetsuro Matsuzawa. 2009. "Social Influences on Ant-Dipping Acquisition in the Wild Chimpanzees (Pan troglodytes verus) of Bossou, Guinea, West Africa." Animal Cognition 12: S37-S48.

Hunnius Sabine, and Harold Bekkering. 2010. "The Early Development of Object Knowledge: A Study of Infants' Visual Anticipations During Action Observation.” Developmental Psychology 46: $446-454$.

Inoue-Nakamura, Noriko, and Matsuzawa Tetsuro. 1997. "Development of Stone Tool Use by Wild Chimpanzees.” Journal of Comparative Psychology 11: 159-173.

Jaeggi, Adrian V., Dunkel, Lynda P., van Noordwijk, Maria A., Wich, Serge A., Sura, Agnes A. L. and van Schaik, Carel P. 2010. "Social Learning of Diet and Foraging Skills by Wild Immature Bornean Orangutans: Implications for Culture. American Journal of Primatology 72 : $62-71$. 
Julien, Michèle, and Claudine Karlin. 2015. "Un Automne à Pincevent : Le Campement Magdalénien du Niveau IV20." Les Nouvelles de l'Archaéologie 139: 5-11.

Kahrs, Björn and Lockman, Jeffrey J. 2014. “Tool Using.” Child Development Perspectives 8: 231-236.

Kamp, Katherine. 2015. "Children and their Childhoods: Retrospectives and Prospectives." Childhood in the Past 8: 161-169.

Karlin, Claudine, and Julien Michèle. 1994. "Prehistoric Technology: A Cognitive Science?” In The Ancient Mind: Elements of Cognitive Archaeology, edited by Colin Renfrew and Ezra B. W. Zubrow, 152-164. Cambridge: Cambridge University Press

Kenyon, Dienje, and Charles D. Arnold. 1985. "Toys as Indicators of Socialization in Thule Culture." In Status, Structure and Stratification: Current Archaeological Reconstructions, edited by Marc Thompson, Maria Teresa Garcia, and Francois J. Kense, 347-353. Calgary: The Archaeological Association of the University of Calgary.

Keupp, Stefanie, Tanya Behne, Joanna Zachow, Alina Kasbohm, and Hannes Rakoczy. 2015. "Over-Imitation is Not Automatic: Context Sensitivity in Children's Overimitation and Action Interpretation of Causally Irrelevant Actions." Journal of Experimental Child Psychology 130: 163-175.

Konner, Melvin J. 2010. The Evolution of Childhood: Relationships, Emotion, Mind. Cambridge, MA: Belknap Press.

Koops, Kathelijne, Takeshi Furuichi, Chie Hashimoto, and Carel P. van Schaik. 2015. "Sex Differences in Object Manipulation in Wild Immature Chimpanzees (Pan troglodytes schweinfurthii) and Bonobos (Pan paniscus): Preparation for Tool Use?" PLOS ONE 10 (10): e0139909. 
Lancy, David F. 1996. Playing on the Mother Ground: Cultural Routines for Children's

Development. New York, NY: Guilford.

Lancy, David F. 2010. “Learning 'From Nobody:' The Limited Role of Teaching in Folk Models of Children's Development." Childhood in the Past 3: 79-106.

Lancy, David F. 2015a. The Anthropology of Childhood: Cherubs, Chattel, Changelings, $2^{\text {nd }}$ edition. Cambridge: Cambridge University Press.

Lancy, David F. 2015b. “Children as a Reserve Labor Force.” Current Anthropology 56: 545-568.

Lancy, David F. 2016. "Playing with Knives: The Socialization of Self-Initiated Learners." Child Development 87: 654-665.

*Lave, Jean, and Etienne Wenger. 1991. Situated Learning: Legitimate Peripheral Participation. Cambridge: Cambridge University Press.

Leroi-Gourhan, André. 1964. Le Geste et la Parole I: Technique et Langage, Paris: A. Michel.

Liebenberg, Louis. 1990. The Art of Tracking. Cape Town, South Africa: Creda Press.

Lonsdorf, Elizabeth V. 2005. "Sex Differences in the Development of Termite-Fishing Skills in the Wild Chimpanzees of Gombe National Park, Tanzania." Animal Behavior 70: 673-683.

Lonsdorf, Elizabeth V. 2006. "What is the Role of Mothers in the Acquisition of Termite-Fishing Behaviors in Wild Chimpanzees?" Animal Cognition 9: 36-46.

Lupo, Karen D. and Dave N. Schmitt. 2002. "Upper Paleolithic Net-Hunting, Small Prey Eeploitation, and Women's Work Effort: A View from the Ethnographic and Ethnoarchaeological Record of the Congo Basin." Journal of Archaeological Method and Theory 9 (2): 147-179. 
Marlowe, Frank W. 2010. The Hadza: Hunter-Gatherers of Tanzania. Berkeley, CA: University of California Press.

Marshall-Pescini, Sarah, and Andrew Whiten. 2008. "Social Learning of Nut-Cracking Behavior in East African Sanctuary-Living Chimpanzees.” Journal of Comparative Psychology 122: 186194.

Matsuzawa, Tetsuro. 1994. "Field Experiments on Use of Stone Tools by Chimpanzees in the Wild." In Chimpanze Cultures, edited by Richard Wrangham, W.C. McGrew, Frans B. M. de Waal, and Paul G Heltne, 351-370. Cambridge, MA: Harvard University Press.

Matsuzawa, Tetsuro, Dora Biro, Tatyana Humle, Noriko Inoue-Nakamura, Rikako Tonooka, and Gen Yamakoshi. 2001. "Emergence of Culture in Wild Chimpanzees: Education by MasterApprenticeship.” In Primate Origins of Human Cognition and Behavior, edited by Tetsuro Matsuzawa, 557-574. New York: Springer.

Maynard, Ashley E. 2002. "Cultural Teaching: The Development of Teaching Skills in Maya Sibling Interactions." Child Development 7: 969-982.

McGrew, William C. 1993. "The Intelligent Use of Tools: Twenty Propositions.” In Tools, Language and Cognition in Human Evolution, edited by Kathleen R. Gibson, \& Tim Ingold, 151-170. Cambridge, New York: Cambridge University Press.

Meltzoff, Andrew N. 2002. "Elements of a Developmental Theory of Imitation." In The Imitative Mind: Development, Evolution and Brain Bases, edited by Andrew N. Meltzoff, Wolfgang Prinz, and George Butterworth, 19-41. Cambridge: Cambridge University Press.

Ochs, Elinor, and Carolina Izquierdo. 2009. "Responsibility in Childhood: Three Developmental Trajectories." Ethos 37: 391-413. 
Odden, Harold, and Phillipe Rochat. 2004. "Observational Learning and Enculturation.” Educational and Child Psychology 21: 39-50.

Paradise, Ruth, and Barbara Rogoff. 2009. "Side by Side: Learning by Observing and Pitching In." Ethos 37: 102-138.

Park, Robert W. 2005. "Growing up North: Exploring the Archaeology of Childhood in the Thule and Dorset Cultures of Arctic Canada." In Children in Action: Perspectives on the Archaeology of Childhood, edited by J. E. Baxter. Vol. 15 of Archeological Papers of the American Anthropological Association, 153-164.

Petraglia, Michael D., Ceri Shipton, and K.Paddyya. 2005. "Life and Mind in the Acheulian: A Case Study from India." In The Hominid Individual in Context: Archaeological investigations of Lower and Middle Paleolithic Landscapes, Locales and Artifacts, edited by Clive Gamble and Martin Porr, 197-219. London: Routledge.

Pigeot, Nicole. 1990. “Technical and Social Actors: Flint Knapping Specialists at Magdalenian Etiolles." Archaeological Review from Cambridge 9: 126-141.

Politis, Gustavo G. 2007. Nukak: Ethnoarchaeology of an Amazonian People. Translated by Benjamin Alberti. Walnut Creek, CA: University College London Institute of Archaeology Publications.

Putt, Shelby S., Alexander D. Woods, and Robert G. Franciscus. 2014. "The Role of Verbal Interaction During Experimental Bifacial Stone Tool Manufacture.” Lithic Technology 39: 96112.

Rheingold, Harriet. 1982. "Little Children's Participation in the Work of Adults: A Nascent Prosocial Behavior.” Child Development 53: 114-125. 
Rochat, Phillipe. 1989. "Object Manipulation and Exploration in 2- to 5-Month-Old Infants." Developmental Psychology 25: 871-884.

Rogoff, Barbara, Ruth Paradise, Rebeca Arauz, Méjia Correa-Chavez, and Cathy Angelillo. 2003. "Firsthand Learning through Intent Participation." Annual Review of Psychology 54: 175203.

Sanz, Crickette M. and David B. Morgan. 2014. "The Social Context of Chimpanzee Tool Use." In Tool Use in Animal: Cognition and Ecology, edited by Crickette M. Sanz, Josep Call, and Christophe Boesch, 161-175. New York: Cambridge University Press.

Schulz, Laura E., and Elizabeth B. Bonawitz. 2007. "Serious Fun: Preschoolers Engage in More Exploratory Play when Evidence is Confounded.” Developmental Psychology 43: 1045-1050.

Shelley, Phillip H. 1990. "Variation in Lithic Assemblages: An Experiment." Journal of Field Archaeology 17: 187-193.

Shipton, Ceri, and Mark Nielsen. In press. "The Acquisition of Biface Knapping Skill in the Acheulean.” In The Evolution of Primate Social Cognition, edited by F. D. Vincenzo. Heidelberg, DE: Springer.

Stahl, Aimee E., and Lisa Feigenson. 2015. “Observing the Unexpected Enhances Infants' Learning and Exploration.” Science 348: 91-94.

Stapert, Dick. 2007. "Neanderthal Children and Their Flints.” Pal/Arch's Journal of Archaeology of Northwest Europe 1(2): 16-38.

Stout, Dietrich. 2002. "Skill and Cognition in Stone Tool Production: An Ethnographic Case Study from Irian Jaya.” Current Anthropology 43: 693-715. 
Stout, Dietrich, and Sileshi Semaw. 2006. "Knapping Skills of the Earliest Stone Age Toolmakers." In The Oldowan: Case Studies Into the Earliest Stone Age, edited by Nicholas Toth and Kathy Schick, 307-320. Gosport, IN: Stone Age Institute Press.

Tayanin, Damrong, and Kristina Lindell. 1991. Hunting and Fishing in a Kammu Village.” Studies in Asian Topics, no. 14. Copenhagen, Denmark: Curzon Press.

Thomas, Kelly. 2005. "The 'Nature' of Childhood: Ethnography as a Tool in Approaching Children in Archaeology." Archaeological Papers of the American Anthropological Association 15: $27-40$.

Thompson, Jennifer L., and Andrew J. Nelson. 2011. "Middle Childhood and Modern Human Origins." Human Nature 22: 249-280.

Warneken, Felix and Michael Tomasello. 2009. "The Roots of Human Altruism.” British Journal of Psychology 100: 455-471.

Weisfeld, Glenn E., and Harold E. Linkey. 1985. "Dominance Displays as Indicators of a Social Success Motive. In Power, Dominance, and Nonverbal Behavior, edited by Steve L. Ellyson, and John F. Dovidio, 109-128. New York: Springer-Verlag.

White, J. Peter, Nicholas Modjeska, and Irari Hipuya. 1977. "Group Definitions and Mental Templates." In Stone Tools as Cultural Markers, edited by R. V. S. Wright, 380-90. Atlantic Highlands, NJ: Humanities Press.

Whiten, Andrew. 2002. "The Imitator's Representation of the Imitated: Ape and Child." In The Imitative Mind: Development, Evolution and Brain Bases, edited by Andrew N. Meltzoff, Wolfgang Prinz, and George Butterworth, 98-121. Cambridge: Cambridge University Press.

Whiting, John W.M. 1941. Becoming a Kwoma. New Haven,CT: Yale University Press. 
Wilhelm, J. H. 1953. Die Kung-Buschleute. Leipzig: Jahrbuch des Museums das Völkerkunde 12: 91-189.

Yamamoto, Shinya, Gen Yamakoshi, Tatanya Humle, Tetsuro Matsuzawa. 2008. "Invention and Modification of a New Tool-Use Behavior: Ant-Fishing in Trees by a Wild Chimpanzee (Pan troglodytes verus) at Bossou, Guinea." American Journal of Primatolology 70: 699-702. doi: 10.1002/ajp.20544. 